\title{
Health promotion in elderly people: an experience report in the central region of the city of Rio De Janeiro, Brazil
}

\begin{abstract}
Elderly health promotion programs are important, especially with the accelerated population aging process in Brazil. The objective was to present the Federal University of Rio de Janeiro (UFRJ) Nutrition undergraduate students and professors experience report on the health promotion of the Carioca Health Gymnastic Program (PACAS) elderly participants in Rio de Janeiro, Brazil. The target population was composed of 60 elderly individuals with or without cardiovascular comorbidity and who practices physical exercises with two weekly classes in the PACAS, linked to a Municipal Health Center, in the central region of the city of Rio de Janeiro. The health popular education planned method perspective aimed at introducing the food and nutrition theme in a continuous way in the PACAS. The actions of health education were mainly conversation wheels, dialogued exposition, sensory experimentation activities. An important action developed in this partnership and generating unfolding was the implementation of the community vegetable garden. It was held weekly meetings in the second half of 2016 between the users and the UFRJ Nutrition undergraduate students as one of the social actors involved, besides elderly and the physical education professionals. It's important to emphasize the intergenerational and social promotion importance, contributing to the elderly people life quality improvement. PACAS should not be restricted to physical practices and activities. It's necessary to have a multidisciplinary and inter-sectors articulation with nutrition. The reflections generated during the activities confirmed the importance of nutritional education as a tool for health promotion in the elderly. The experience of integrating postgraduate students with health promotion activities in a multidisciplinary perspective, based on popular education, was positive and aggregating. Interdisciplinary experience and practices in health, based on the knowledge and experience of all actors involved, should be encouraged and essential in the training of students and in the coresponsibility of teachers with health services.
\end{abstract}

Keywords: aged, health promotion, health services for the aged

\section{Introduction}

The accelerated population aging process in Brazil and the chronic disease increase in the last decade brings society challenges, especially in the health field, on services growing demand and its organization as much as in the need of professional training. In this context, elderly health promotion programs are more important every day, expanding health practices and care from the different socioeconomic and cultural factors perspective in each it is inserted.

Aiming to stimulate people to grow old in a different healthier way, the Brazilian Health Ministry came up with a group of actions that can contribute in a considerable way to the well being and life quality of the Brazilian elder population. ${ }^{2}$ Among the propositions are the physical exercise stimulation and the healthy eating, and one of the most important is the Health Gymnastic Program (Programa Academia da Saúde - PAS), created in April, 2011. ${ }^{3}$

The PAS consists in public spaces which are characterized as Health Assistance Network attention areas. Its aim is the health promotion contribution from a health life styles encouragement in the Basic Attention and to extend the population access to the health promotion policies and the population global attention promotion in each Health Unit territory. 3,4
Volume I Issue 6 - 2017

\author{
Aline Alves Ferreira, Raquel de Souza \\ Mezzavilla ,Viviane Marinho da Costai \\ Instituto de Nutrição Josué de Castro, Universidade Federal do \\ Rio de Janeiro, Brazi
}

Correspondence: Aline Alves Ferreira. Josué de Castro Nutrition Institute, Federal University of Rio de Janeiro, Brazil, Email alineaf@nutricao.ufrj.br

Received: July 0I, 20I I | Published: August 10, 2017
The PAS was initiated in 2009 in Rio de Janeiro and has the name Carioca Health Gymnastic Program (Programa Academia Carioca da Saúde - PACAS). It is currently expanding and also aims the physical activity regular practice increase, as well as the health promotion actions in Primary Care effectiveness and efficacy, by strengthening intersectoral actions and healthy lifestyles knowledge capillarization. This program is open to the population, but it serves predominantly the elder $(97.8 \%))^{5,6}$

It is understood that PACAS should not be restricted to physical practices and physical activities in the elderly, because despite of these initiatives name and importance, it is necessary to have a multidisciplinary and intersectoral articulation for the health promotion in Brazil, especially in this age segment. All actions developed in the Program must be culturally inserted and adapted to the local territories, respecting the sociodiversity existing in the country. ${ }^{7}$

The PACAS is essential for the food and nutrition actions development, because it is an excellent space for food and nutritional surveillance (example: monitoring of weight gain), characterizing itself as an important place for the healthy food adequate promotion. Thus, the objective was to present the Federal University of Rio de Janeiro 
Nutrition (UFRJ) undergraduate students and professors experience report on the health promotion of Carioca Health Gymnastic Program (Programa Academia Carioca da Saúde - PACAS) elderly participants in Rio de Janeiro, Brazil.

\section{Case presentation}

The target population was composed of elderly individuals with or without cardiovascular comorbidity and who practices physical exercises with two weekly classes in the Carioca Health Gymnastic Program (Programa Academia Carioca da Saúde - PACAS), linked to the Municipal Health Center (Centro Municipal de Saúde - CMS) Ernesto Zeferino Tibau Junior, in the central region of the city of Rio de Janeiro, Brazil. It is a region with low living conditions, violence, low purchasing power and basic sanitation problems.

The territory where PACAS is located has limited access to commercial establishments with fruit and vegetable varieties and a high supply of ultra processed products, such as sugary and salty drinks which corroborates the greater access to exposure to unhealthy eating habits. Social violence and urban design affect the elderly living in this territory quality of life, food and health. Despite these limitations, the promotion and encouragement of people to choose healthier eating are necessary in the food environment in which they are inserted.

The PACAS, on the spot, is composed of approximately 60 participants who voluntarily enroll in the program each semester, between 50 and 88 years of age (mean of 65 years of age), women elderly (90\%), residents of the region of São Cristóvão and surrounding areas. There is a relay between program participants; however, the follow-up is longitudinal, since they are enrolled in the program and monitored to achieve goals of improving nutritional status and indicators, health related especially hypertension and diabetes (prevalent diseases in the group).

The physical educator develops with the participants effortless physical activities in specific fitness equipment allocated in the area of the academy. In addition to stretching and relaxation activities, they occasionally engage in outdoor activities such as walking and hiking.

The meetings periodicity with the users was weekly, for one hour, and occurred in the second half of 2016, with the Federal University of Rio de Janeiro Nutrition undergraduate students as one of the social factors involved, as well as the elderly and physical education professionals.

Regarding the partnership between the undergraduate nutrition course and the PACAS, the activities are carried out by trainees in the sixth period and students are mainly focused on the Promotion of Adequate and Healthy Food (PAHF). The students in the eight period work with PACAS on specific projects, once per semester, and in this period develop more punctual actions, always accompanied by a supervising professor. The undergraduate students were always supervised by professor in the discussion of ideas and production of materials for the meetings, with sporadic participation of the physical educator of the Health Unit. The objective of this partnership is to enable students to work in health promotion and PAHF, while for PACAS this partnership makes it possible to expand the possibilities of changes in the habits that imply the health problems of the program participants.

Facing this scenario, the health popular education planned method perspective, aimed at introducing the food and nutrition theme in a continuous way in the PACAS and were used educational strategies of demonstration, experimentation/experience, oral history, panel construction, conversations and culinary workshops. Among the topics addressed, we highlight:

i. Healthy and adequate food

ii. Reduction of consumption of ultra processed and processed foods

iii. Reduction of consumption of food ingredients, such as salt, sugars and fats

iv. Eating habits and their relation with chronic diseases

v. Cooking as a space for promoting healthy eating

vi. Food labeling and food choices.

The actions of health education were mainly conversation wheels, dialogued exposition, sensory experimentation activities (taste, smell). These activities allowed the use of several teachinglearning methodologies, using the topics of interest of the participants as a proposal for the subsequent activities, and valuing the popular knowledge brought by them as a way of building shared knowledge.

The activities were held in the open air, in a territory square, and complemented by an educational material made by Nutrition professionals and undergraduate students, based on the scientific literature and the availability of culinary recipes.

One of the activities main products was the Health Unit where the PACAS takes place community vegetable garden construction and maintenance. The strategy was developed in partnership between the Health Unit staff, the PACAS elderly participants and the university students and professors, based on intersectoral work, articulating university projects (agroecology and non-conventional food plants) and the network (such as fairs and markets in the PACAS territory). This action was developed through intersectoral articulations between several projects and institutes of the University, involved in various fields of knowledge, such as nutrition, gastronomy, agronomy and agroecology. Of these partnerships, not only the theoretical-practical scope was developed for the development of the vegetable garden, but also it was possible to raise donations of inputs for such construction. This action was aimed at stimulating the creation of home vegetable gardens and the consumption of natural foods and without additives, inducing the reduction of consumption of ready-made spices, for example. For this reason, the genera planted in the vegetable garden were mostly natural seasonings, but also aromatic and suitable herbs for teas, as well as some Unconventional Food Plants (UFPs). This vegetable garden, developed and deployed collectively, receives maintenance from the PACAS participants, who not only maintain it but also consume it.

\section{Discussion}

The Health Gymnastics Program (PAS), called the Carioca Health Gymnastics Program (Programa Academia Carioca da Saúde PACAS) in Rio de Janeiro and financed by the Health Ministry has as main objective to contribute to the health promotion of the population. It also care production and healthy lifestyles of the population from the implantation of poles with infrastructure and qualified professionals focused on the practice of physical activity. ${ }^{3}$ 
For the actions implementation in the PACAS, public squares spaces were created with devices in the city of Rio de Janeiro different regions, always linked to Health Units. These spaces are composed of at least ten devices that allow the practice of aerobic exercises and simple anaerobes that can be performed by anyone, including those with reduced mobility. Some places have multiprofessional teams, where there is also activities such as capoeira, ballroom dancing, yoga among others offered. ${ }^{7}$ Studies point to the Program's potential as a strategy for health promotion and care production in the communities, with the elderly being one of the priority publics. ${ }^{4}$

Despite being addressed to the entire population, PAS and PACAS are composed, mostly by the elderly, especially in large cities, such as Rio de Janeiro. Considering that most of the activities are directed addressed the elderly, and that these represent a growing segment of the country population, it is important to emphasize the promotion of intergenerational and social importance contributing to the improvement of the quality of life, Preservation of functional capacity, muscle strengthening and motor coordination.

The activities in food and nutrition developed in the PACAS had a broader focus than only the incentive to the physical activity practice, being of great importance for the strengthening of the National Food and Nutrition Policy (NFNP) and, consequently, of the country Unified Health System (UHS). ${ }^{8}$ The actions provide the social actors involved a differentiated experience in which the humanization aspect is highlighted, emphasizing the dialogue and listening exercise, the bonds creation, the relationship with the other and the different realities and contexts of life of the elderly confrontation. ${ }^{9}$ All the initiatives combined the activities of the surveillance and health care areas, with health promotion as the main axis.

The educational actions in health in the elderly context should be based on health different determinants, considering the histories of life, beliefs, customs and values of each individual. Thus, it is expected that the individual's reflection on his lifestyle and the perception of health as a social right will be stimulated. ${ }^{9}$ Therefore, professionals working in the PACAS must be attentive to each elderly person and have an open user's participation posture, continuously seeking the construction of shared actions that promote the healthy ways of living construction.

As an example of this educational actions, we have the maintenance of the vegetable garden. Elderly, undergraduate students and health and physical education professionals have been keeping the vegetable garden in the Health Unit until today. It has been used by all users and has been maintained at the initiative of the PACAS participants themselves. In their opinion, the vegetable garden was useful to give life to the place and possibility of easier vegetables. Some photos can be seen below (Figure 1-3).

Especially in the work with the elderly, there is a communicative process that needs constant attention if the equality opportunities conditions is guaranteed to the participants. Thus, language care is necessary to facilitate the appropriation and understanding of new knowledge. ${ }^{10}$

In this sense, the work developed with the partnership between the University and the Health Unit was based on the dialogues construction that favored the elderly public subjects of interest and the traditional food practices appreciation as a way of healthy eating promoting based on real food and cooking. In all these discussion spaces that were promoted, active listening and the experiences exchange were privileged as a way of approaching and reaching the main aspects to be considered in order to reflect on the group in question eating habits.

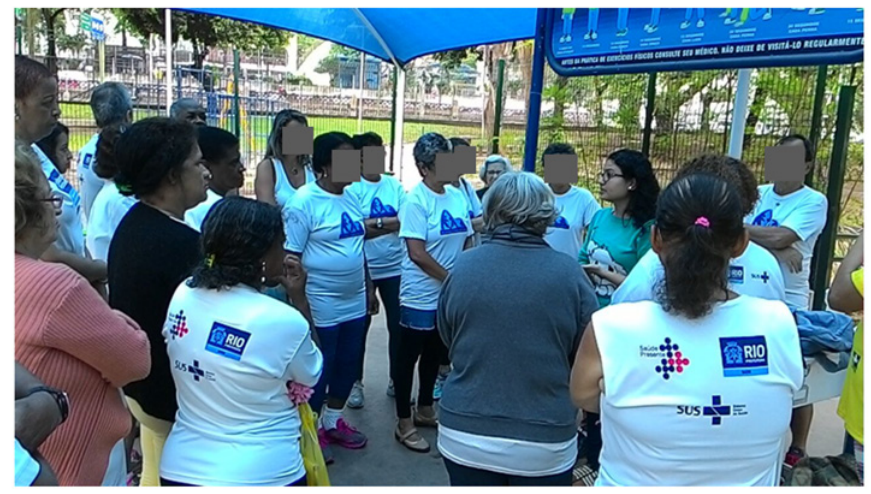

Figure I Educational actions during the practice of physical activity. PACAS, Rio de Janeiro, 2016 (Photo by Jessyca Lima).

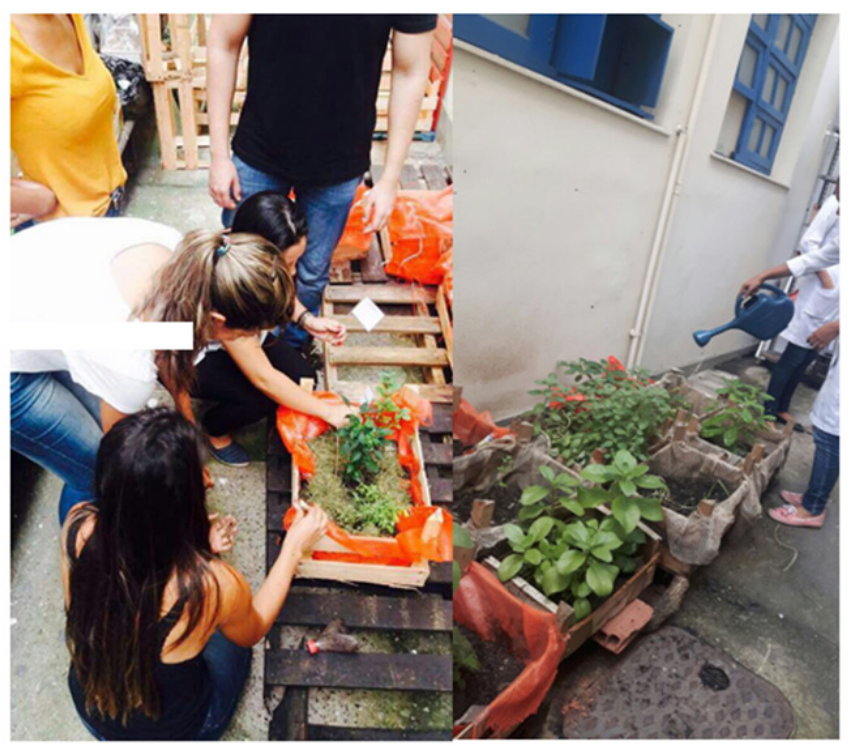

Figure 2 Maintenance of the vegetable garden. Rio de Janeiro, 2016 (Photo by Claudia Zilves).

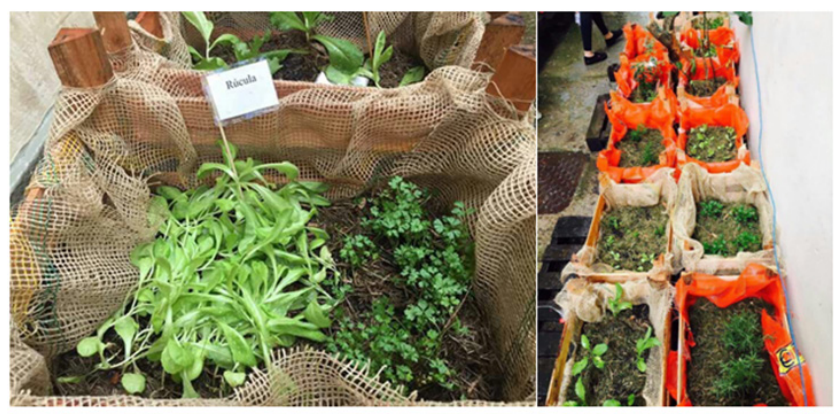

Figure 3 Vegetable garden. Rio de Janeiro, 2016 (Photo by Claudia Zilves).

It is worth mentioning that the construction and permanent maintenance of the vegetable garden are activities which provide the elderly with moments of socialization, integration and belonging to the group and the community, as well as the perception of being active. 


\section{Conclusion}

The reflections generated during the activities confirmed the importance of nutritional education as a tool for health promotion in the elderly, and how the media and advertising influence the food choices of the majority of the population, demonstrating the need for stimulus to purchase more healthy food.

Despite the offer of activities of corporal practices in PACAS, actions to promote healthy eating and health education actions are still incipient, especially if approached in an integrated way. The meetings that took place were important not only from this perspective, but also from the health team and education qualification.

The experience of integrating graduate students with health promotion activities in a multidisciplinary perspective, based on popular education, was positive and aggregator. The experience and interdisciplinary practices in health, based on the knowledge and experience of all the actors involved should be encouraged being essential in the training of students and in the co-responsibility of the teachers with the health services.

\section{Acknowledgements}

None.

\section{Conflict of interest}

Authors declare there is no conflict of interest in composing this manuscript.

\section{References}

1. Alcântara AO, Camarano AA, Giacomin KC. National politics of the elderly: old and new issues. Ipea, Rio de Janeiro, Brazil; 2016. p. 615.
2. Ministry of Health $(\mathrm{MOH})$. Health Surveillance Secretariat. National Health Promotion Policy (PNaPS): revision of Ordinance MS / GM No. 687, Brazil; 2014. p. 34.

3. Ministry of Health (MOH). Secretariat of Health Surveillance. Evaluation of Effectiveness of Physical Activity Programs in Brazil, Brazil; 2011. p. 182.

4. Sá GBAR, Dornelles GC, Cruz KG, et al. The Health Academy Program as a strategy for health promotion and healthy lifestyles: national implementation scenario. Ciênc saúde coletiv. 2016;21(6):1849-1859.

5. Ministry of Health (MOH). Secretariat of Health Surveillance. Department of Surveillance of Noncommunicable Diseases and Diseases and Health Promotion. National overview of the implementation of the Health Academy Program: national monitoring of the management of the Health Academy Program. cycle 2016, Brazil; 2017. p. 95.

6. Padilha MA, Padilha CMO, Figueiró AC. Evaluation study of the Carioca Health Academy Program: challenges for the promotion of health. Saúde debat. 2015;39(105):375-386.

7. Fraga AB, Lopes ACS, Pinto ALS, et al. Extension course in health promotion for SUS managers focusing on the health academy program. Ministry of Health, Brazil; 2013. p. 146.

8. Ministry of Health $(\mathrm{MOH})$. Secretariat of Health Care, 2nd edn. Department of Basic Attention. National Food and Nutrition Policy. Brazil; 2013. p. 86.

9. Machado MFAS, Monteiro EMLM, Queiroz DT, et al. Integrality, health education, health education and SUS proposals: a conceptual review. Ciência \& Saúde Coletiva. 2007;12(2):335-342.

10. Albuquerque PC, Stotz EN. Popular education in basic health care in the municipality: in search of integrality. Interface. 2004;8(15):259-274. 